\title{
A Relação da Acreditação com 0 Isomorfismo Institucional e com os Artefatos de Contabilidade Gerencial nos Hospitais da Região Sul do Brasil
}

\author{
Marcia Zanievicz da Silva ${ }^{1}$ \\ Andréia Carpes Dani² \\ Cleston Alexandre dos Santos ${ }^{3}$
}

http://dx.doi.org/10.21527/2237-6453.2018.44.562-597

Recebido em: 13/6/2016

Aceito em: 14/8/2017

\begin{abstract}
Resumo
Este artigo tem por objetivo verificar a relação da acreditação hospitalar com o isomorfismo institucional e com os artefatos tradicionais e modernos de contabilidade gerencial em hospitais da Região Sul do Brasil. 0 estudo, que se caracteriza como descritivo, documental e quantitativo, foi realizado durante os meses de novembro e dezembro de 2015, e obteve 42 retornos. Os resultados revelam que as mudanças trazidas pelo isomorfismo normativo são causadas pela semelhança de objetivos entre as profissões e profissionais, procedimentos e resultados. Assim, a adoção voluntária a um processo de certificação de acreditação hospitalar ocorre em virtude de um fator normativo externo legitimado na visão dos profissionais da área, além de estar atrelada a uma necessidade interna e estratégica. Conclui-se que existe uma relação entre a certificação de acreditação dos hospitais analisados, as pressões isomórficas e 0 uso de artefatos tradicionais e modernos de contabilidade gerencial.
\end{abstract}

Palavras-chave: Acreditação hospitalar. ONA. Artefatos de contabilidade gerencial. Isomorfismo institucional. Gestão de hospitais.

1 Doutora em Ciências Contábeis e Administração, professora do Programa de Pós-Graduação em Ciências Contábeis da Universidade Regional de Blumenau. marciaza@gmail.com

2 Doutoranda em Ciências Contábeis e Administração pela Universidade Regional de Blumenau. andreiacarpesdani@gmail.com

3 Doutorando em Ciências Contábeis e Administração pela Universidade Regional de Blumenau. cleston.alexandre@hotmail.com 


\title{
RELATIONSHIP AMONG ACCREDITATION, INSTITUTIONAL ISOMORPHISM AND MANAGEMENT ACCOUNTING ARTIFACTS IN SOUTHERN BRAZIL HOSPITALS
}

\begin{abstract}
The paper aims to investigate the relationship of hospital accreditation with institutional isomorphism and traditional and modern management accounting artifacts in southern Brazil hospitals. The study is characterized as descriptive, documental and quantitative, was conducted during the months of November and December, 2015, and obtained 42 responses. The results show that changes brought by the normative isomorphism are caused by the similarity of objectives between the professions and professional procedures and results. Thus, the voluntary adoption of a hospital accreditation and certification process occurs due to an external normative factor legitimized in the eyes of professionals, besides being linked to an internal and strategic necessity. It is concluded that there is a relationship between the accreditation of certification of the surveyed hospitals, isomorphic pressures and the use of traditional and modern artifacts of management accounting.
\end{abstract}

Keywords: Hospital accreditation. ONA. Management accounting artifacts. Institutional isomorphism. Hospital management. 
$\mathrm{O}$ atual mundo globalizado tem exigido das organizações que repensem suas práticas gerenciais e estratégias para alcançarem resultados positivos e se manterem competitivas no mercado. Dessa forma, a escolha por uma estratégia específica exige flexibilidade e capacidade de adaptação, o que pode requerer a adoção de artefatos de contabilidade gerencial que atenda a demandas de informações específicas (ESPEJO et al., 2009). Otley (1994) ressalta a importância da contabilidade gerencial, pois a evidencia como detentora dos principais artefatos de controle de gestão.

Souza, Lisboa e Rocha (2003) destacam que a contabilidade gerencial tem sido apresentada como um meio eficiente e eficaz de geração de informações utilizadas pelos gestores organizacionais. Nesse contexto, as organizações e gestores de hospitais tomam decisões e aderem a práticas de gestão em razão de melhores resultados econômicos, e ainda, buscam a acreditação hospitalar com o propósito de uma melhor gestão dos recursos e a oferta de serviços com maior qualidade (ROGGENKAMP; WHITE; BAZZOLI, 2005).

A acreditação contribui para que os hospitais aperfeiçoem e promovam a melhoria na qualidade do atendimento ao paciente, o que exige mudança na cultura das organizações e qualificação dos processos internos (ALONSO et al., 2014; XAVIER; CARMO FILHO, 2015). A acreditação hospitalar consiste em um sistema de avaliação e certificação da qualidade de serviços de saúde, que é voluntário, periódico e reservado, cuja ação é conduzida por uma organização ou agência não governamental responsável pela disseminação e instituição da sua metodologia (NOVAES, 2007; ORGANIZAÇÃO..., 2010; ALONSO et al., 2014; XAVIER; CARMO FILHO, 2015).

A acreditação hospitalar engloba toda a organização, da estrutura ao processo de controle do planejamento estratégico, destacando-se que, para a elaboração do planejamento, os membros que fazem parte da gestão demandam por artefatos de contabilidade gerencial tradicionais e/ou modernos que sejam adequados à atividade e à necessidade informacional (NOVAES, 2007; XAVIER; CARMO FILHO, 2015). Roggenkamp, White e Bazzoli 
(2005) afirmam que as organizações hospitalares instituem novas práticas gerenciais, que contribuem para a melhoria de seus processos internos e resultados, visando a alcançar a certificação por acreditação hospitalar.

Tendo em vista a revisão de literatura e os achados de Xavier e Carmo Filho (2015) de que há diferença no uso dos artefatos de contabilidade entre as organizações hospitalares acreditadas e as não acreditadas, e os de Cardoso e Martins (2012) de que o processo de acreditação hospitalar influência na utilização e gestão dos artefatos de custos, inclusive na redução de custos operacionais, Garrido, Tacchini e Saltorato (2014) sugerem que o processo de acreditação é algo institucionalizado nas organizações hospitalares, e ocorre em virtude da legitimação pela sobrevivência. Mamedio (2014) aduz que existe uma influência do processo de isomorfismo institucional sobre o processo de acreditação hospitalar.

Constata-se que são três os fatores que influenciam as práticas de gestão no sentido da mudança, que são caracterizadas como pressões coercivas, pressões normativas ou processos miméticos (GRANLUND; LUKKA, 1998; DOS REIS; REIF; MARASSI, 2015). Sob a ótica do isomorfismo institucional, a adesão aos valores e preceitos estabelecidos pela acreditação hospitalar representa um mecanismo de difusão social, legitimidade e sobrevivência (GARRIDO; TACGHINI; SALTORATO, 2014).

A literatura evidencia a necessidade de ampliar os estudos sobre a gestão das organizações hospitalares, como também pesquisas que evidenciem a relevância da acreditação hospitalar e sua influência no processo organizacional (VIANA et al., 2011; ALONSO et al., 2014). Partindo-se do exposto por Viana et al. (2011) e Garrido, Tacchini e Saltorato (2014), de que a acreditação tem como missão garantir a qualidade nos serviços hospitalares prestados e gerar benefícios institucionais, bem como de conduzir a uma melhor gestão dos recursos e a tomada de decisão gerencial, diversos autores evidenciam a importância de identificar e compreender os fatores que influenciam a adoção dos artefatos de contabilidade gerencial, uma vez que as organizações estão inseridas em um ambiente em constante proces- 
so de transformação, a exemplo das pesquisas de Otley (1994), Guerreiro, Frezatti e Casado (2006), Espejo (2008), Espejo et al. (2009) e Guerreiro, Cornachione Jr. e Soutes (2011).

Desta reflexão surge a seguinte questão de pesquisa: Qual a relação da acreditação hospitalar com o isomorfismo institucional e com os artefatos de contabilidade gerencial em hospitais da Região Sul do Brasil? Nessa perspectiva, o objetivo da pesquisa é verificar a relação da acreditação hospitalar com o isomorfismo institucional e com os artefatos tradicionais e modernos de contabilidade gerencial em hospitais da Região Sul do Brasil.

Foram identificados apenas duas pesquisas na área, porém, quanto aos hospitais não acreditados, Xavier e Carmo Filho (2015) restringiram o estudo para as organizações da cidade de Manaus (AM) e Cardoso e Martins (2012) para a cidade de Uberlândia (MG), abordando apenas sistemas de custeio. Devido à não identificação de outras pesquisas na área e na Região Sul do país, o presente estudo se diferencia dos mencionados, pois visa a contribuir com a identificação de uma possível relação da acreditação hospitalar com o isomorfismo institucional e os artefatos tradicionais e modernos da contabilidade gerencial. Xavier e Carmo Filho (2015) encontram evidências de que hospitais acreditados utilizam artefatos gerenciais diferenciados em comparação com aqueles que não possuem a certificação. E ainda, os autores observam que há poucas pesquisas explorando e argumentando sobre os benefícios oriundos após a acreditação hospitalar.

De modo semelhante a um dos propósitos dos estudos de Garrido, Tacchini e Saltorato (2014) e de Xavier e Carmo Filho (2015), busca-se valorizar as interpretações subjetivas das ações organizacionais, visando a uma melhor compreensão da forma como os hospitais se posicionam diante das pressões isomórficas em favor do aprimoramento da qualidade dos serviços prestados. 


\section{Fundamentação Teórica}

\section{Modelos de Certificação de Acreditação Hospitalar e Isomorfismo}

A acreditação hospitalar é um processo de avaliação externa, por meio do qual uma organização avalia, periodicamente, as organizações de saúde para determinar se estas atendem a um conjunto de padrões concebidos para melhorar a qualidade do cuidado ao paciente (O'BRIEN; RENNEBOHM; LOWE, 1987; NOVAES, 2007; HEUVEL; NIEMEIJER; DOES, 2013; ALONSO et al., 2014; MAMEDIO, 2014).

A origem da acreditação hospitalar está associada à necessidade de qualidade na prestação de serviços e melhoria na assistência à saúde pelas organizações hospitalares em diversos países. Com a evolução e padronização dos processos, diferentes modelos de qualidade desenvolvidos têm sido adotados por organizações de saúde, aprimorando a definição de critérios, indicadores e padrões dos serviços de saúde (CARDOSO; MARTINS, 2012; NIEMEIJER, 2012; MORAIS et al., 2015). Gryna, Chua e Defeo (2007) e Niemeijer (2012) destacam que as atividades hospitalares podem fornecer provas para que seja estabelecida a confiança de que os requisitos de qualidade serão totalmente satisfeitos.

No Brasil, no período entre 1998 e 1999, o Ministério da Saúde realizou o projeto de divulgação da "Acreditação no Brasil”, por meio de um ciclo de palestras realizado nas 27 capitais com objetivo de melhorar a compreensão sobre o Sistema Brasileiro de Acreditação e sua forma de operacionalização. Esse projeto culminou com a criação da entidade Organização Nacional de Acreditação (ONA), em maio de 1999 (FELDMAN; GATTO; CUNHA, 2005; XAVIER; CARMO FILHO, 2015; MORAIS et al., 2015). Entre os métodos de avaliação da qualidade em saúde, existem alguns modelos de certificação de acreditação hospitalar que podem ser 
utilizados no Brasil entre os quais: a Organização Nacional de Acreditação (ONA), Health Services Accreditation (IQG), Joint Commission International (JCI) e a Accreditation Canada International ou Sistema Canadense de Acreditação.

De acordo com dados do IQG (HEALTH..., 2016), as organizações hospitalares brasileiras possuem uma quantidade de hospitais acreditados, respectivamente de: 36 organizações acreditadas pela JCI; 14 são acreditadas pelo IQG; 290 organizações acreditadas pela ONA, das quais 3 possuem selo de Qualificação ONA, 53 são acreditados no Nível 1, 97 no Nível 2 e 137 no Nível 3. Conforme observado, os modelos mais recorrentes, adotados por organizações hospitalares brasileiras, são o da ONA e da JCI. Conforme dados contidos nos sites das referidas organizações, no ano de 2015 haviam 290 hospitais brasileiros acreditados, 36 deles na Região Sul (ORGANIZAÇÃO..., 2015). Dada a maior expressividade de filiações à ONA, o presente estudo passa a focalizar esse sistema de acreditação como variável de análise.

A ONA é uma entidade não governamental e sem fins lucrativos que certifica a qualidade de serviços de saúde no Brasil, com foco na segurança do paciente. Tem como objetivo promover um processo constante de avaliação e aprimoramento nos serviços de saúde e, dessa forma, melhorar a qualidade da assistência no país (ALONSO et al., 2014; ORGANIZAÇÃO..., 2015).

O processo de acreditação está pautado em três princípios fundamentais: é voluntário, feito por escolha da organização de saúde; é periódico, com avaliação das organizações de saúde para certificação e durante o período de validade do certificado; é reservado, ou seja, as informações coletadas em cada organização de saúde no processo de avaliação não são divulgadas (ORGANIZAÇÃO..., 2015). A certificação pode ocorrer em três níveis, favorecendo a melhora contínua da gestão, conforme demonstra o Quadro 1. 


\section{Quadro 1 - Níveis de Acreditação da ONA}

\begin{tabular}{|l|l|l|}
\hline $\begin{array}{l}\text { Níveis de Certi- } \\
\text { ficação }\end{array}$ & \multicolumn{1}{|c|}{ Descrição } & Validade \\
\hline 1- Acreditada & $\begin{array}{l}\text { Para instituições que atendem aos critérios de } \\
\text { segurança do paciente em todas as áreas de ati- } \\
\text { vidade, incluindo aspectos estruturais e assis- } \\
\text { tenciais. }\end{array}$ & 2 anos \\
\hline $\begin{array}{l}\text { 2- Acreditada } \\
\text { Pleno }\end{array}$ & $\begin{array}{l}\text { Para instituições que, além de atenderem aos } \\
\text { critérios de segurança, apresentam gestão in- } \\
\text { tegrada, com processos ocorrendo de maneira } \\
\text { fluida e plena comunicação entre as atividades. }\end{array}$ & 2 anos \\
\hline $\begin{array}{l}\text { 3- Acreditada } \\
\text { com Excelência }\end{array}$ & $\begin{array}{l}\text { O princípio deste nível é a “excelência em ges- } \\
\text { tão". Uma organização ou programa da saúde } \\
\text { acreditado com excelência atende aos níveis 1 } \\
\text { e 2, além dos requisitos específicos de nível 3. } \\
\text { A instituição já deve demonstrar uma cultura } \\
\text { organizacional de melhoria contínua com matu- } \\
\text { ridade institucional. }\end{array}$ & 3 anos \\
\hline
\end{tabular}

Fonte: Adaptado de ONA (ORGANIZAÇÃO..., 2015).

Considerando que o $3^{\circ}$ nível de Acreditação prima pela excelência em gestão, supõe-se que, conforme os hospitais vão evoluindo de um nível de acreditação para outro, ocorra também uma utilização diferenciada de artefatos de contabilidade gerencial, capazes de contribuir com o processo de gerenciamento, dada as demandas informacionais requeridas.

Nesse contexto, muitas estruturas organizacionais formais surgem como reflexos de regras institucionais racionalizadas (MEYER; ROWAN, 1977; DOS REIS; REIF; MARASSI, 2015). Dimaggio e Powel (1983, 2005) apresentam três mecanismos de mudança isomórfica institucional nas organizações, sendo: o isomorfismo coercitivo, o isomorfismo mimético e o isomorfismo normativo. Os autores explicam que o isomorfismo coercitivo deriva de influências, problemas de legitimidade ou de pressões formais e informais exercidas por outras organizações. Dimaggio e Powel (1983, 2005) enfatizam que a imposição direta de procedimentos operacionais padronizados e de regras e estruturas legitimadas também ocorre fora da arena governamental. 
O isomorfismo mimético resulta de respostas padronizadas às incertezas. Neste, as organizações tomam outras como modelo, constituindo uma resposta à incerteza. De modo geral, quanto mais ampla a quantidade de pessoas empregadas ou de clientes servidos por uma organização, maior será a pressão sentida por esta para oferecer os programas e serviços disponibilizados por outras organizações. Assim, essas organizações tomam como modelo outras mais antigas (DIMAGGIO; POWEL, 1983, 2005). Já o isomorfismo normativo está associado à profissionalização, ou seja, refere-se às pressões sofridas pelas categorias profissionais, podendo ser designado pelo Estado ou criado pelas atividades das categorias (DIMAGGIO; POWEL, 1983, 2005).

No contexto das organizações hospitalares, a busca pela adequação aos méritos prezados pela norma de acreditação hospitalar "tornou-se algo já institucionalizado na sociedade. As pressões sobre as organizações hospitalares em favor do aprimoramento de suas práticas deixam de advir apenas das exigências legais e governamentais» (GARRIDO; TACCHINI; SALTORATO, 2014, p. 10). A certificação serve como um mecanismo de difusão social, que fornece um exame comum de produtos e organizações (BAUM, 2010). Para Garrido, Tacchini e Saltorato (2014), é possível considerar a certificação da acreditação como uma busca por eficiência simbólica. Nessa visão, a aderência aos valores e preceitos estabelecidos pela acreditação hospitalar não são apenas ação técnica, mas uma busca pela legitimidade e pela sobrevivência na sociedade, ou seja, uma busca por uma eficiência simbólica. Assim, "a condição de 'acreditada' não deixa de ser um mecanismo de difusão social, legitimidade e sobrevivência, o que transparece a superficialidade das abordagens predominantes acerca do tema» (GARRIDO; TACCHINI; SALTORATO, 2014, p. 1).

Mamedio (2014) ao analisar a influência do processo de isomorfismo institucional, no processo de acreditação hospitalar de um hospital de média e alta complexidade da cidade de Curitiba, verificou que houve isomorfismo do tipo normativo, considerando a busca pela legitimidade 
por meio da profissionalização do hospital, com o objetivo de demonstrar qualidade, segurança e excelência no serviço prestado, alcançando assim o conceito pelo qual esta organização foi criada, ou seja, a garantia de referência hospitalar.

Tendo em vista a revisão de literatura realizada, sugere-se que a acreditação é algo institucionalizado nas organizações hospitalares, e a busca pela acreditação hospitalar ocorre em virtude da legitimação pela sobrevivência e competitividade ao mesmo tempo que busca demonstrar qualidade e excelência nos serviços prestados. A partir da revisão de literatura, surge a seguinte hipótese de pesquisa:

\section{$H_{1}:$ Existe relação entre a certificação de acreditação dos hospitais da região Sul do Brasil e as pressões isomórficas.}

A não rejeição da hipótese $H_{1}$ indicará que os hospitais da Região Sul do Brasil que possuem certificação de acreditação hospitalar são afetados pelas regras institucionais racionalizadas, seja por isomorfismo coercitivo, isomorfismo mimético ou por isomorfismo normativo. Dessa forma, é esperado que o isomorfismo institucional nas organizações hospitalares influencie para o alcance da certificação de acreditação dos hospitais.

\section{Gestão Hospitalar e Artefatos da Contabilidade Gerencial}

Qualquer que seja a organização, para o estabelecimento de um sistema de gestão torna-se primordial uma reflexão sobre o tipo de informação necessária. Diante da quantidade de dados a serem explorados, a entidade deve optar e registrar apenas as informações que são compatíveis com o desempenho e que possam contribuir para a gestão, o que exige uma hierarquização das informações utilizadas (EMÍDIO et al., 2013). 
No caso dos hospitais, atividade que contempla processos complexos, exige um nível de especialização na área da gestão, até então pouco explorado (MEZOMO, 1992; EMÍDIO et al., 2013). Harris (1977) evidencia que o hospital é uma organização com atividades específicas e projetadas para resolver problemas de decisão complicada, que parte do diagnóstico e segue para o tratamento da doença. Em razão da incerteza inerente aos processos que envolvem doenças, a tarefa exige da organização a adoção de inovações tecnológicas, artefatos de gestão, e que se adapte rapidamente a novas circunstâncias (HARRIS, 1977). Otley (1994) destaca que em atividades que contemplam ambiente volátil e incerto, o controle de gestão deve possibilitar que a organização desenvolva suas operações de forma mais eficiente com o propósito de controlar o seu futuro.

O processo decisório hospitalar está diretamente ligado à contabilidade gerencial, cuja área é interpretada por Horngren, Sundem e Stratton (2004) como detentora de artefatos que identificam, mensuram, acumulam, analisam, preparam, interpretam e comunicam informações com o propósito de auxiliar os gestores para alcançarem os objetivos organizacionais pré-estabelecidos. No entendimento de Louderback, Holmen e Dominiak (2000), a contabilidade gerencial tem como pressuposto prover informações que deem apoio às necessidades e objetivos dos gestores internos da entidade. Espejo et al. (2009) argumentam que para alcançar os objetivos organizacionais preestabelecidos, é primordial que a contabilidade gerencial, por meio de seus artefatos, leve em consideração todas as diferenças das necessidades informacionais dos usuários.

Artefatos de contabilidade gerencial são entendidos como sendo sistemas de informação, modelos de gestão, sistemas de custeio, filosofias instituídas pelas organizações e conceitos de mensuração e avaliação de desempenho, que possam ser explorados pelos gestores no desenvolvimento de suas atividades (FREZATTI, 2005; GUERREIRO; CORNACHIONE JR.; SOUTES, 2011). 
Os artefatos de contabilidade gerencial tradicionais compreendem o Custeio Padrão, Custeio por Absorção, Custeio Variável, Descentralização, Moeda Constante, Orçamento, Preço de Transferência, Retorno sobre Investimento e Valor Presente. Já como artefatos de contabilidade gerencial modernos tem-se o Balanced Scorecard (BSC), Benchmarking, Custeio Baseado em Atividades (ABC), Custeio Meta, Gestão Baseada em Atividade (ABM), Economic Value Added (EVA), Gestão Baseada em Valor (VBM), Just in Time (JIT), Kaizen, Planejamento Estratégico, Simulação e Teoria das Restrições (SOUZA; LISBOA; ROCHA, 2003; FREZATTI, 2005; GUERREIRO; CORNACHIONE JR.; SOUTES, 2011; VERHAGEM, 2011; RODNISKI et al., 2014; XAVIER; CARMO FILHO, 2015; DOS SANTOS; DOROW; BEUREN, 2016; SANT'ANA; SANTOS; CUNHA, 2017).

Diversos autores (KAPLAN, 1983; LUCAS, 1997; SULAIMAN; NAZLI NIK AHMAD; ALWI, 2004) têm argumentado que as técnicas tradicionais, tais como o Custo Padrão, Orçamento Tradicional e Análise Custo-Volume-Lucro não são mais adequadas para serem usadas como ferramentas de planejamento e controle. Por outro lado, há autores (LUCAS, 1997; SULAIMAN; NAZLI NIK AHMAD; ALWI, 2004) que defendem que para a obtenção de sucesso, no atual ambiente de negócios que é dinâmico, a organização precisa direcionar suas estratégias para a melhoria da qualidade e aumento da flexibilidade no atendimento das necessidades individuais dos clientes. Nesse cenário, Sulaiman, Nazli Nik Ahmad e Alwi (2004) argumentam que artefatos como o ABC e Custeio Meta contribuem para aumentar consideravelmente a capacidade das organizações para cumprirem os seus objetivos.

Souza, Lisboa e Rocha (2003) argumentam que para uma maior contribuição na busca da eficácia organizacional, a contabilidade gerencial demanda um desenvolvimento constante de artefatos, como também a seleção dos que efetivamente atendem às necessidades informacionais e que sejam interpretados e utilizados de forma adequada. Vale destacar que a 
influência institucional, na mudança organizacional, pode estar integrada em um paradigma de adoção de práticas inovadoras de gestão (ROGGENKAMP; WHITE; BAZZOLI, 2005).

A convergência das práticas de gestão é influenciada por pressões coercivas, pressões normativas ou processos miméticos (GRANLUND; LUKKA, 1998). A contabilidade gerencial é destacada por Burns e Scapens (2000) como uma instituição dentro da empresa, isto é, uma rotina formada por hábitos que dá sentido a determinado grupo de pessoas, com esta estrutura organizacional sendo aceita de forma inquestionável.

Com base no exposto, as organizações hospitalares e seus administradores são levados a tomar várias decisões organizacionais, como também a efetivar práticas de gestão justificadas por situações em prol de um melhor resultado, e em paralelo, para contribuir nos processos do controle interno e na melhor forma de utilização dos recursos disponíveis, buscam a acreditação hospitalar (ROGGENKAMP; WHITE; BAZZOLI, 2005).

Tendo em vista a revisão de literatura e os achados de que há diferença no uso dos artefatos de contabilidade entre as organizações hospitalares acreditadas e as não acreditadas (XAVIER; CARMO FILHO, 2015) e de que o processo de acreditação hospitalar influencia na utilização e gestão dos artefatos de custos, inclusive na redução de custos operacionais (CARDOSO; MARTINS, 2012), surgem as seguintes hipóteses desta pesquisa:

$H_{2 a}:$ Existe relação entre a certificação de acreditação dos hospitais da Região Sul do Brasil e a utilização de artefatos tradicionais de contabilidade gerencial.

$H_{2 b}$ : Existe relação entre a certificação de acreditação dos hospitais da Região Sul do Brasil e a utilização de artefatos modernos de contabilidade gerencial.

A não rejeição da hipótese $H_{2 a}$ indicará que os hospitais da Região Sul do Brasil que possuem certificação de acreditação hospitalar fazem uma maior adoção de artefatos tradicionais de contabilidade gerencial do 
que os hospitais que não possuem acreditação. Dessa forma, é esperado que a acreditação hospitalar aumente a adoção dos artefatos tradicionais de contabilidade gerencial.

A não rejeição da hipótese $H_{2 b}$ indicará que os hospitais da Região Sul do Brasil que possuem certificação de acreditação hospitalar fazem uma maior adoção de artefatos modernos de contabilidade gerencial do que os hospitais que não possuem acreditação. Dessa forma, é esperado que a acreditação hospitalar aumente a adoção dos artefatos modernos de contabilidade gerencial.

\section{Metodologia da Pesquisa}

Esta pesquisa caracteriza-se como descritiva, realizada por meio de levantamento, e a abordagem do problema é quantitativa. Para a definição da população verificou-se as informações no site do Departamento de Informática do SUS (Datasus), na base do Cadastro Nacional de Estabelecimentos de Saúde (CNES), quanto aos hospitais do Sul do Brasil cadastrados. Levando em consideração o banco de dados citado, a população da pesquisa foi composta por 210 hospitais pertencentes às capitais e às cidades com mais de 100 mil habitantes. Dessa forma, a amostra final da pesquisa é composta por 42 hospitais.

Para a coleta dos dados identificou-se por meio do site do Datasus e base CNES os números dos telefones dos 210 hospitais pertencentes à população da pesquisa. Na sequência, fez-se contato telefônico com o contador, ou controller, ou diretor financeiro de cada um dos hospitais da amostra. No contato foi explicado o objetivo do estudo, como também a realização do convite para participação da pesquisa. Após o aceite, o instrumento de pesquisa on-line foi encaminhado ao endereço eletrônico de cada entidade, cuja coleta compreendeu o período de 4/11/2015 a 23/12/2015. 
O instrumento de pesquisa é formado por três blocos de questões e totaliza 50 questões fechadas, com o primeiro bloco sendo elaborado pelos autores, o segundo adaptado a partir dos estudos de Santos (2008) e Verhagem (2011) e o terceiro bloco desenvolvido a partir da pesquisa de Xavier e Carmo Filho (2015), conforme o Quadro 2.

Quadro 2 - Constructo da Pesquisa

\begin{tabular}{|c|c|c|c|c|c|}
\hline Bloco & Categorias & Subcategorias & Questões & Proxy & Autores \\
\hline \multirow{2}{*}{ I } & \multirow{2}{*}{$\begin{array}{l}\text { Perfil Institu- } \\
\text { cional }\end{array}$} & $\begin{array}{l}\text { Caracterização } \\
\text { do respondente }\end{array}$ & 1 a 3 & Alternativas & $\begin{array}{l}\text { Elaborado pelos } \\
\text { autores. }\end{array}$ \\
\hline & & $\begin{array}{c}\text { Caracterização } \\
\text { do hospital }\end{array}$ & 4 a 9 & Alternativas & $\begin{array}{l}\text { Elaborado pelos } \\
\text { autores. }\end{array}$ \\
\hline \multirow{3}{*}{ II } & \multirow{3}{*}{ Isomorfismo } & Ambiente & $10 \mathrm{a} 13$ & $\begin{array}{l}\text { Escala likert de } \\
5 \text { pontos: muito } \\
\text { baixo (1), baixo } \\
\text { (2), indiferen- } \\
\text { te (3), alto (4) e } \\
\text { muito alto (5) }\end{array}$ & \multirow[t]{3}{*}{$\begin{array}{l}\text { Santos (2008); } \\
\text { V e r h a g e m } \\
(2011) \text {. }\end{array}$} \\
\hline & & $\begin{array}{l}\text { Causas de im- } \\
\text { plementação }\end{array}$ & 14 a 21 & \multirow{2}{*}{$\begin{array}{l}\text { Escala likert de } 5 \\
\text { pontos: discordo } \\
\text { totalmente (1), } \\
\text { discordo (2), } \\
\text { indiferente (3), } \\
\text { concordo (4) e } \\
\text { concordo total- } \\
\text { mente (5) }\end{array}$} & \\
\hline & & $\begin{array}{l}\text { Postura do } \\
\text { profissional }\end{array}$ & 22 a 29 & & \\
\hline \multirow[b]{2}{*}{ III } & \multirow[b]{2}{*}{$\begin{array}{l}\text { Artefatos de } \\
\text { Contabilida- } \\
\text { de Gerencial }\end{array}$} & $\begin{array}{l}\text { Artefatos tradi- } \\
\text { cionais }\end{array}$ & 30 a 38 & \multirow{2}{*}{$\begin{array}{l}\text { Escala de } 5 \\
\text { pontos: não } \\
\text { há planos para } \\
\text { adotar (1), ava- } \\
\text { liou e descartou } \\
\text { a adoção (2), } \\
\text { em processo de } \\
\text { avaliação (3), } \\
\text { adoção inicial (4) } \\
\text { e adoção plena } \\
\text { (5) }\end{array}$} & \multirow{2}{*}{$\begin{array}{l}\text { Souza, Lisboa } \\
\text { e Rocha (2003); } \\
\text { Frezatti (2005); } \\
\text { Guerreiro, } \\
\text { Cornachione Jr, } \\
\text { e Soutes (2011); } \\
\text { Verhagem } \\
\text { (2011); Xavier } \\
\text { e Carmo Filho } \\
(2015) \text {. }\end{array}$} \\
\hline & & $\begin{array}{l}\text { Artefatos mo- } \\
\text { dernos }\end{array}$ & 39 a 50 & & \\
\hline
\end{tabular}

Fonte: Elaborado pelos autores.

$\mathrm{Na}$ análise dos dados utilizou-se a técnica estatística de KrusKal-Wallis e Análise de Correspondências Múltiplas. O teste de Kruskal-Wallis é um método usado para testar se duas ou mais amostras provêm de uma mesma população ou de populações diferentes (Maroco, 2007). Para aná- 
lise descritiva e do teste Kruskal-Wallis empregou-se o software Statistical Package for Social Science (SPSS) versão 22.0. Foi aplicada também a Análise de Correspondências Múltiplas (ACM), com a utilização do software SPSS versão 22.0, cuja técnica se concentra na relação entre variáveis qualitativas, e que possibilita ao pesquisador visualizar associações, por meio de mapas perceptuais, que oferecem a noção de proximidade (FÁVERO et al., 2009).

\section{Análise dos Dados}

Neste tópico são apresentados os resultados obtidos por meio das respostas do questionário on-line enviado aos hospitais da Região Sul do Brasil. No bloco I do questionário - perfil institucional - focalizou as características dos respondentes (42), dos quais 61,9\% (26) possuem a Graduação em Ciências Contábeis, 28,6\% (12) em Administração e 9,5\% (4) em outras áreas. Em relação ao tempo de atuação nos hospitais, constatou-se que a maioria dos respondentes trabalha há mais de 5 anos $(62,5 \%)$ e a função exercida por estes é, na maioria, como contador $(54,8 \%)$.

Em relação às características dos hospitais, observou-se que 33,3\% possuem entre 100 e 199 leitos e que a maioria presta serviços de alta complexidade $(42,9 \%)$. Entre os 42 hospitais analisados, verificou-se que $45,2 \%$ (19) possuem certificação por acreditação hospitalar ativa, dos quais 19 acreditados pela ONA e 1 acreditado pela JCI e ONA - dupla acreditação. Dos acreditados pela ONA, 31,6\% possuem o Nível 1 de acreditação (Acreditada), 36,8\% possuem o Nível 2 (Acreditada Pleno) e 31,6\% o Nível 3 (Acreditada com Excelência).

A maior taxa de certificação pela ONA, comparativamente à JCI, indica haver um interesse predominante na certificação nacional, talvez em virtude de características de organizações do mesmo setor, ou devido a exigências de mercado e clientes nacionais relacionadas à qualidade nos serviços prestados ou, ainda, o custo para a acreditação. Dessa forma, infere-se 
que os hospitais analisados buscam atender a exigências condizentes com o mercado nacional e não às exigências diferenciadas do mercado externo, ou do próprio órgão de certificação internacional.

Posteriormente fez-se a análise da percepção dos respondentes sobre a condição de adaptação ao ambiente no qual a organização está inserida. Para tanto, esse bloco de questões foi realizado com o intuito de analisar a capacidade das organizações em se ajustar e adaptar ao ambiente. Diante dos resultados verificou-se que nos hospitais analisados o ambiente foi classificado como estável e previsível, com um grau de concordância em média de 3,63. Sendo assim, no estudo o ambiente organizacional dos hospitais é categorizado como normativo.

Isso deve-se às mudanças provocadas pelo ambiente externo que influenciam no ambiente organizacional interno dos hospitais. Entre essas salienta-se a necessidade de certificação por acreditação, no sentido de que as organizações adotem novas práticas gerenciais e operacionais internas objetivando o estabelecimento de padrões de qualidade. No caso brasileiro, pode-se considerar que isso ocorreu devido ao fato de um órgão responsável, a ONA, predizer padrões de qualidade para que os processos sejam organizados de um determinado modo (MCKINLEY; MONE, 2003). Sendo assim, o isomorfismo normativo é caracterizado quando há um conjunto de mesmas normas e regras que regem instituições ou organizações similares em atuação.

De modo geral, esses resultados apontam que existe uma influência entre a certificação de acreditação dos hospitais brasileiros da Região Sul e as pressões isomórficas normativas. Dessa forma, não é possível rejeitar a hipótese $H_{l}$, de que existe relação entre a certificação de acreditação dos hospitais da Região Sul do Brasil e as pressões isomórficas.

Os resultados encontrados corroboram com os achados de Mamedio (2014), no sentido de que o isomorfismo do tipo normativo é caracterizado como a busca pela legitimidade por meio da profissionalização dos hospi- 
tais, na busca por demonstrar qualidade, segurança e excelência no serviço prestado, alcançando assim o objetivo pelo qual esta organização foi criada, a garantia de referência hospitalar.

Considera-se que o comportamento de aceitação e legitimação de processos pelas organizações hospitalares que possuem atuação similar ocorreu em virtude do estabelecimento pela ONA de um conjunto de normas e regras e de padrões de qualidade para os processos hospitalares. $\mathrm{Ou}$ seja, as pressões exercidas pela ONA por intermédio de regras e normas influenciaram na mudança de comportamento conjunto das organizações hospitalares de forma similar visando à profissionalização.

Na sequência, na Tabela 1, é descrito o tempo de acreditação dos hospitais analisados, segregados por tipo de complexidade de atendimento que prestam (alta, média ou baixa complexidade).

Tabela 1 - Hospitais, por tipo de complexidade de atendimento e tempo decorridos

\begin{tabular}{|c|c|c|c|c|c|}
\hline $\begin{array}{c}\text { Tempo de } \\
\text { Acreditação }\end{array}$ & $\begin{array}{c}\text { Baixa Com- } \\
\text { plexidade }\end{array}$ & $\begin{array}{c}\text { Média Com- } \\
\text { plexidade }\end{array}$ & $\begin{array}{c}\text { Alta Com- } \\
\text { plexidade }\end{array}$ & $\begin{array}{c}\text { Frequên- } \\
\text { cia Abso- } \\
\text { luta }\end{array}$ & $\begin{array}{c}\text { Frequên- } \\
\text { cia Rela- } \\
\text { tiva }\end{array}$ \\
\hline Até 3 anos & 4 & 1 & 2 & 7 & $37 \%$ \\
\hline De 4 a 6 anos & 1 & 2 & 1 & 4 & $21 \%$ \\
\hline De 7 a 9 anos & 0 & 1 & 6 & 7 & $37 \%$ \\
\hline Acima de 9 anos & 0 & 1 & 0 & 1 & $5 \%$ \\
\hline Total & 5 & 5 & 9 & 19 & \\
\hline
\end{tabular}

Fonte: Dados da Pesquisa.

Verifica-se que dos 45,2\% (19) hospitais acreditados, cerca de $37 \%$ possuem certificação num período de até 3 anos, ou de 7 a 9 anos. A partir desses dados pressupõe-se que, embora a certificação no Brasil já exista há cerca de 16 anos, o nível de adesão ainda é baixo, principalmente pelos hospitais de baixa (5) e média (5) complexidade. Supõe-se que a certificação é mais facilmente adotada pelos hospitais de média e alta complexidade, visto que organizações de porte maior dispõem de uma quantidade de controles 
internos e de ferramentas gerenciais condizentes com a complexidade de seus processos. Essas ferramentas ou artefatos gerenciais possibilitam a manutenção e influenciam na qualidade dos serviços. Num segundo momento, Bloco II do questionário, o tema é a análise do isomorfismo. Sob o enfoque da teoria institucional, o ambiente organizacional sofre influência em decorrência de diversos fatores internos e externos, que ao longo do tempo causam mudanças nas organizações. Assim, a teoria institucional preconiza que as organizações tendem a se adequar a esses fatores.

$\mathrm{Na}$ Tabela 2 apresenta-se os fatores que motivaram a certificação por acreditação pelos hospitais brasileiros acreditados da Região Sul do Brasil.

Tabela 2 - Fatores que impulsionaram a acreditação na organização

\begin{tabular}{|c|l|c|c|c|c|}
\hline \multicolumn{2}{|c|}{ Tipo de Fator } & $\begin{array}{c}\text { Mé- } \\
\text { dia }\end{array}$ & $\begin{array}{c}\text { Me- } \\
\text { diana }\end{array}$ & $\begin{array}{c}\text { Máxi- } \\
\text { mo }\end{array}$ & $\begin{array}{c}\text { Desvio } \\
\text { Padrão }\end{array}$ \\
\hline $\mathbf{1}$ & $\begin{array}{l}\text { Pressão de grupos externos interessa- } \\
\text { dos na organização. }\end{array}$ & 2,79 & 2,00 & 5,00 & 1,55 \\
\hline $\mathbf{2}$ & $\begin{array}{l}\text { Relação de dependência com os gru- } \\
\text { pos externos interessados na organi- } \\
\text { zação. }\end{array}$ & 2,74 & 2,00 & 5,00 & 1,28 \\
\hline $\mathbf{3}$ & $\begin{array}{l}\text { O conteúdo das práticas é consisten- } \\
\text { te com os objetivos da organização. }\end{array}$ & 3,37 & 4,00 & 5,00 & 1,38 \\
\hline $\mathbf{4}$ & $\begin{array}{l}\text { O conteúdo das práticas tem como } \\
\text { objetivo restringir (impor limites) as } \\
\text { ações da organização. }\end{array}$ & 2,53 & 2,00 & 5,00 & 1,26 \\
\hline $\mathbf{5}$ & $\begin{array}{l}\text { As práticas são impostas de forma } \\
\text { obrigatória à organização (pela ges- } \\
\text { tão). }\end{array}$ & 2,74 & 2,00 & 5,00 & 1,45 \\
\hline $\mathbf{6}$ & $\begin{array}{l}\text { Essas práticas são propagadas natu- } \\
\text { ralmente dentro do setor econômico } \\
\text { devido ao seu conteúdo. }\end{array}$ & 3,26 & 4,00 & 5,00 & 1,10 \\
\hline $\mathbf{7}$ & $\begin{array}{l}\text { A organização está conectada ao mer- } \\
\text { cado, às necessidades dos clientes, } \\
\text { aos competidores, etc. }\end{array}$ & 3,37 & 4,00 & 5,00 & 1,30 \\
\hline $\mathbf{8}$ & Por imposição legal (pela legislação). & 2,53 & 2,00 & 5,00 & 1,50 \\
\hline
\end{tabular}

Fonte: Dados da Pesquisa. 
Verifica-se que entre os fatores causadores da certificação, destacam-se: os conteúdos das práticas são consistentes com os objetivos da organização (causa 3); essas práticas são propagadas naturalmente dentro do setor econômico devido ao seu conteúdo (causa 6); a organização está conectada ao mercado, às necessidades dos clientes, aos competidores, etc. (causa 7).

De modo geral percebe-se que a maioria dos respondentes concordam que as mudanças visando à acreditação hospitalar são influenciadas por fatores relacionados ao modelo de gestão, às necessidades dos clientes e do mercado, bem como à postura das demais empresas do mesmo setor, que estão sujeitas aos mesmos procedimentos e que possuem objetivos comuns. Dessa forma, caracteriza-se que as empresas analisadas sofrem pressões características do isomorfismo normativo. As pressões normativas estão relacionadas aos embates da semelhança de objetivos entre as profissões e profissionais, procedimentos e resultados, bem como está associado às pressões sofridas pelas categorias profissionais, que podem ser determinadas pelo estado ou por atividades da categoria (DIMAGGIO; POWEL, 1983, 2005). Sobretudo, a certificação por acreditação não é impulsionada por pressões legais obrigatórias.

$\mathrm{Na}$ Tabela 3 apresenta-se a atuação do profissional diante da acreditação e da alteração de práticas gerenciais ocorridas. Para tanto foram considerados hospitais que possuem a acreditação, bem como aqueles que ainda não são acreditados. 
Tabela 3 - Postura profissional diante da mudança ou alteração de práticas gerenciais no ambiente institucional

\begin{tabular}{|c|c|c|c|c|c|c|c|c|}
\hline \multirow[t]{2}{*}{ Postura } & \multicolumn{2}{|c|}{ Média } & \multicolumn{2}{|c|}{ Mediana } & \multicolumn{2}{|c|}{ Máximo } & \multicolumn{2}{|c|}{$\begin{array}{l}\text { Desvio } \\
\text { Padrão }\end{array}$} \\
\hline & ACR & NCR & ACR & NGR & ACR & NCR & ACR & NGR \\
\hline $\begin{array}{l}\text { Aceito mudanças, pois repre- } \\
\text { sentam os sistemas e as métricas } \\
\text { que devem ser utilizadas nesta } \\
\text { atividade econômica. }\end{array}$ & 3,42 & 3,52 & 4,00 & 4,00 & 5,00 & 5,00 & 1,35 & 1,12 \\
\hline $\begin{array}{l}\text { Aceito as mudanças, pois é o } \\
\text { sistema utilizado na maioria das } \\
\text { organizações deste setor econô- } \\
\text { mico. }\end{array}$ & 3,74 & 3,87 & 4,00 & 4,00 & 5,00 & 5,00 & 1,19 & 0,92 \\
\hline $\begin{array}{l}\text { Aceito as mudanças, pois é o sis- } \\
\text { tema que trará benefícios para } \\
\text { a organização, já que a gestão } \\
\text { da organização busca estrate- } \\
\text { gicamente utilizar as melhores } \\
\text { práticas. }\end{array}$ & 3,74 & 3,87 & 4,00 & 4,00 & 5,00 & 5,00 & 1,19 & 1,06 \\
\hline $\begin{array}{l}\text { Adoto parcialmente as práticas } \\
\text { do processo de convergência, } \\
\text { faço o estritamente necessário } \\
\text { para acomodar as necessidades } \\
\text { legais da organização. }\end{array}$ & 1,95 & 3,00 & 2,00 & 3,00 & 5,00 & 5,00 & 1,08 & 1,51 \\
\hline $\begin{array}{l}\text { Mantenho minhas discordâncias } \\
\text { e restrições quanto às mudanças } \\
\text { em silêncio; quando auditado ou } \\
\text { questionado faço comentários } \\
\text { e relatórios só para manter os } \\
\text { questionamentos. }\end{array}$ & 2,11 & 2,13 & 2,00 & 2,00 & 5,00 & 5,00 & 1,15 & 1,22 \\
\hline $\begin{array}{l}\text { Ignoro as demandas relaciona- } \\
\text { das às mudanças, o risco de ser } \\
\text { punido por não utilizá-las é mí- } \\
\text { nimo, ou as consequências de } \\
\text { desconsiderá-las são pequenas e } \\
\text { administráveis. }\end{array}$ & 2,21 & 2,17 & 2,00 & 2,00 & 5,00 & 5,00 & 1,23 & 1,19 \\
\hline $\begin{array}{l}\text { Negocio com os demais gestores } \\
\text { a relação custo/ benefício de al- } \\
\text { gumas práticas. }\end{array}$ & 3,53 & 3,30 & 4,00 & 4,00 & 5,00 & 5,00 & 1,22 & 1,22 \\
\hline $\begin{array}{l}\text { Contesto as pressões exerci- } \\
\text { das pelas mudanças, em minha } \\
\text { opinião existem bases razoáveis } \\
\text { para a sua não aplicabilidade na } \\
\text { atividade da empresa. }\end{array}$ & 2,68 & 2,78 & 2,00 & 3,00 & 5,00 & 4,00 & 1,49 & 1,31 \\
\hline
\end{tabular}

Legenda: ACR - Acreditado; NCR - Não acreditado.

Fonte: Dados da Pesquisa. 
Buscou-se verificar a postura dos profissionais contábeis diante das novas exigências, e constatou-se que as mudanças das práticas gerenciais advindas desse processo de certificação foram aceitas, tanto para os hospitais acreditados como para aqueles não acreditados, dentro da seguinte visão: aceito as mudanças, pois é o sistema utilizado na maioria das organizações deste setor econômico (causa 2); aceito as mudanças, pois é o sistema que trará benefícios para a organização, uma vez que a gestão da organização busca estrategicamente utilizar as melhores práticas (causa 3); negocio com os demais gestores a relação custo/benefício de algumas práticas (causa 7).

Observa-se que a postura dos profissionais diante da mudança ou alteração de práticas gerenciais no ambiente institucional é semelhante tanto naqueles que atuam em hospitais acreditados como nos não acreditados. Esses resultados sugerem que existe uma tendência quanto à postura dos profissionais, demonstrando uma propensão de comportamento de empresas do setor. Diante disso, constata-se que a adoção voluntária a um processo de certificação de acreditação pelos hospitais busca atender a uma demanda das demais empresas do mesmo setor, em virtude de um fator normativo externo legitimado na visão dos profissionais da área, além de estar atrelada a uma necessidade interna e estratégica.

Confirma-se com isso a necessidade de identificação da estrutura e do campo organizacional, visto que, em um ambiente em que diferentes organizações do mesmo ramo de negócio estão num campo concentrado (por competição, pelo Estado, pelas categorias profissionais) (DIMAGGIO; POWEL, 1983, 2005), percebe-se que a interferência de pressões externas às organizações, relacionadas às características do ambiente interno e externo, conduzem à prática do isomorfismo num ambiente institucional de mudança, que contribui para a compreensão da relação entre estruturas e o amplo ambiente social no qual as organizações estão situadas (CUNHA; SANTOS; BEUREN, 2015). 
De modo geral, verifica-se um comportamento similar na postura profissional diante da mudança ou alteração de práticas gerenciais no ambiente institucional, para aqueles que atuam em hospitais acreditados daqueles que atuam em organizações não acreditadas. Isso sugere haver uma tendência de comportamento similar entre os profissionais do setor, e tal fato pode influenciar não apenas na adoção de novas práticas gerenciais, mas também no aumento de hospitais acreditados no futuro.

No Bloco III da análise dos dados, a Tabela 4 evidencia o grau de adoção dos artefatos tradicionais de contabilidade gerencial.

Tabela 4 - Grau de adoção dos artefatos tradicionais de contabilidade gerencial

\begin{tabular}{|c|c|c|c|c|c|c|c|c|c|c|c|}
\hline & & \multicolumn{6}{|c|}{ Frequência Absoluta } & \multirow[b]{2}{*}{ MÉD } & \multirow[b]{2}{*}{ MED } & \multirow[b]{2}{*}{ MÁX } & \multirow[b]{2}{*}{ DP } \\
\hline \multicolumn{2}{|c|}{ Artefatos Tradicionais } & $\mathbf{N P}$ & AD & PA & AI & $\mathbf{A P}$ & TOT & & & & \\
\hline \multirow{2}{*}{$\begin{array}{l}\text { Custeio } \\
\text { Padrão }\end{array}$} & Acreditados & 5 & 2 & 1 & 5 & 6 & 19 & 3,42 & 4,00 & 5,00 & 1,57 \\
\hline & Não Acreditados & 13 & 5 & 2 & 3 & 0 & 23 & 1,78 & 1,00 & 4,00 & 1,09 \\
\hline \multirow{2}{*}{$\begin{array}{c}\text { Custeio por } \\
\text { Absorção }\end{array}$} & \begin{tabular}{|l|} 
Acreditados \\
\end{tabular} & 1 & 0 & 1 & 2 & 15 & 19 & 4,58 & 5,00 & 5,00 & 1,02 \\
\hline & Não Acreditados & 3 & 3 & 6 & 5 & 6 & 23 & 3,35 & 3,00 & 5,00 & 1,37 \\
\hline \multirow{2}{*}{$\begin{array}{c}\text { Custeio } \\
\text { Variável }\end{array}$} & Acreditados & 6 & 1 & 0 & 4 & 8 & 19 & 3,37 & 4,00 & 5,00 & 1,80 \\
\hline & Não Acreditados & 8 & 2 & 4 & 7 & 2 & 23 & 2,70 & 3,00 & 5,00 & 1,46 \\
\hline \multirow{2}{*}{$\begin{array}{c}\text { Descentralizaç } \\
\text { ão }\end{array}$} & Acreditados & 3 & 0 & 1 & 3 & 12 & 19 & 4,11 & 5,00 & 5,00 & 1,49 \\
\hline & Não Acreditados & 8 & 1 & 5 & 6 & 3 & 23 & 2,78 & 3,00 & 5,00 & 1,51 \\
\hline \multirow{2}{*}{$\begin{array}{c}\text { Moeda } \\
\text { Constante }\end{array}$} & Acreditados & 2 & 0 & 2 & 1 & 14 & 19 & 4,32 & 5,00 & 5,00 & 1,34 \\
\hline & Não Acreditados & 12 & 0 & 4 & 3 & 4 & 23 & 2,43 & 1,00 & 5,00 & 1,65 \\
\hline \multirow{2}{*}{ Orçamento } & Acreditados & 0 & 0 & 1 & 2 & 16 & 19 & 4,79 & 5,00 & 5,00 & 0,54 \\
\hline & Não Acreditados & 3 & 0 & 2 & 4 & 14 & 23 & 4,13 & 5,00 & 5,00 & 1,39 \\
\hline \multirow{2}{*}{$\begin{array}{c}\text { Preço de } \\
\text { Transferência }\end{array}$} & Acreditados & 6 & 2 & 3 & 2 & 6 & 19 & 3,00 & 3,00 & 5,00 & 1,70 \\
\hline & Não Acreditados & 14 & 2 & 2 & 3 & 2 & 23 & 2,09 & 1,00 & 5,00 & 1,47 \\
\hline \multirow{2}{*}{$\begin{array}{c}\text { Retorno s/ } \\
\text { Investimento }\end{array}$} & Acreditados & 5 & 2 & 3 & 6 & 3 & 19 & 3,00 & 3,00 & 5,00 & 1,49 \\
\hline & Não Acreditados & 7 & 2 & 6 & 5 & 3 & 23 & 2,74 & 3,00 & 5,00 & 1,48 \\
\hline \multirow{2}{*}{$\begin{array}{c}\text { Valor } \\
\text { Presente }\end{array}$} & Acreditados & 6 & 1 & 5 & 5 & 2 & 19 & 2,79 & 3,00 & 5,00 & 1,44 \\
\hline & Não Acreditados & 12 & 0 & 7 & 2 & 2 & 23 & 2,22 & 1,00 & 5,00 & 1,41 \\
\hline
\end{tabular}

Legenda: NP e 1 = Não há planos para adoção; AD e 2 = Avaliou e descartou; PA e $3=$ Em processo de avaliação; AI e 4 = Adoção inicial; AP e 5 = Adoção plena; TOT = Total; MÉD = Média; MED = Mediana; DP = Desvio padrão.

Fonte: Dados da Pesquisa.

A média e o baixo desvio padrão revelam que a adoção plena de artefatos tradicionais nos hospitais acreditados tem predominância do Custeio por Absorção $(4,58)$ e o Orçamento $(4,79)$. Já quanto à adoção plena de artefatos nos hospitais não acreditados não foi observada predominância, apenas com adoção inicial, com destaque para o artefato Orçamento $(4,13)$. Com base nos 
dados percebe-se que os hospitais acreditados utilizam ou estão em processo de adoção de uma variedade maior de artefatos de gestão, comparativamente aos não acreditados. Constata-se também que, nos hospitais acreditados, alguns artefatos estão em processo de avaliação, como o Custeio Padrão $(3,42)$, Custeio Variável $(3,37)$, Preço de Transferência $(3,00)$ e Retorno sobre Investimento $(3,00)$. Nas organizações não acreditadas destaca-se o Custeio por Absorção $(3,35)$. Vale ressaltar que há um quantitativo relevante nos artefatos dos hospitais acreditados que estão em processo de avaliação para posterior adoção.

Na sequência a Tabela 5 evidencia o grau de adoção dos artefatos modernos de contabilidade gerencial.

Tabela 5 - Grau de adoção dos artefatos modernos de contabilidade gerencial

\begin{tabular}{|c|c|c|c|c|c|c|c|c|c|c|c|}
\hline \multirow{2}{*}{\multicolumn{2}{|c|}{ Artefatos Modernos }} & \multicolumn{6}{|c|}{ Frequência Absoluta } & \multirow{3}{*}{$\begin{array}{c}\text { MÉD } \\
4,11\end{array}$} & \multirow{3}{*}{$\begin{array}{c}\text { MED } \\
5,00\end{array}$} & \multirow{3}{*}{$\begin{array}{c}\text { MÁX } \\
5,00\end{array}$} & \multirow{3}{*}{$\begin{array}{c}\text { DP } \\
1,20\end{array}$} \\
\hline & & \multirow{2}{*}{$\begin{array}{c}\mathbf{N P} \\
1\end{array}$} & \multirow{2}{*}{$\begin{array}{c}\text { AD } \\
1\end{array}$} & \multirow{2}{*}{\begin{tabular}{|c|} 
PA \\
3
\end{tabular}} & \multirow{2}{*}{\begin{tabular}{|l} 
AI \\
4
\end{tabular}} & \multirow{2}{*}{$\begin{array}{l}\mathbf{A P} \\
10\end{array}$} & \multirow{2}{*}{$\begin{array}{c}\text { TO } \\
\mathbf{T} \\
19\end{array}$} & & & & \\
\hline & Acreditados & & & & & & & & & & \\
\hline BSC & Não Acreditados & 8 & 4 & 4 & 4 & 3 & 23 & 2,57 & 2,00 & 5,00 & 1,47 \\
\hline \multirow{2}{*}{ Benchmarking } & Acreditados & 1 & 0 & 1 & 3 & 14 & 19 & 4,53 & 5,00 & 5,00 & 1,02 \\
\hline & Não Acreditados & 10 & 2 & 2 & 4 & 5 & 23 & 2,65 & 2,00 & 5,00 & 1,70 \\
\hline \multirow{2}{*}{$\mathbf{A B C}$} & Acreditados & 4 & 1 & 2 & 2 & 10 & 19 & 3,68 & 5,00 & 5,00 & 1,67 \\
\hline & Não Acreditados & 12 & 4 & 4 & 2 & 1 & 23 & 1,96 & 1,00 & 5,00 & 1,22 \\
\hline \multirow{2}{*}{ Custeio Meta } & Acreditados & 6 & 2 & 2 & 4 & 5 & 19 & 3,00 & 3,00 & 5,00 & 1,67 \\
\hline & Não Acreditados & 14 & 3 & 4 & 2 & 0 & 23 & 1,74 & 1,00 & 4,00 & 1,05 \\
\hline \multirow{2}{*}{$\mathbf{A B M}$} & Acreditados & 9 & 2 & 1 & 6 & 1 & 19 & 2,37 & 2,00 & 5,00 & 1,50 \\
\hline & Não Acreditados & 13 & 0 & 7 & 3 & 0 & 23 & 2,00 & 1,00 & 4,00 & 1,21 \\
\hline \multirow{2}{*}{ EVA } & Acreditados & 6 & 4 & 4 & 4 & 1 & 19 & 2,47 & 2,00 & 5,00 & 1,31 \\
\hline & Não Acreditados & 15 & 2 & 3 & 3 & 0 & 23 & 1,74 & 1,00 & 4,00 & 1,14 \\
\hline \multirow{2}{*}{ VBM } & Acreditados & 8 & 6 & 3 & 1 & 1 & 19 & 1,89 & 2,00 & 5,00 & 1,15 \\
\hline & Não Acreditados & 16 & 1 & 4 & 2 & 0 & 23 & 1,65 & 1,00 & 4,00 & 1,07 \\
\hline \multirow{2}{*}{ JIT } & Acreditados & 8 & 9 & 2 & 0 & 0 & 19 & 1,68 & 2,00 & 3,00 & 0,67 \\
\hline & Não Acreditados & 15 & 4 & 2 & 2 & 0 & 23 & 1,61 & 1,00 & 4,00 & 0,99 \\
\hline \multirow{2}{*}{ Kaizen } & Acreditados & 12 & 4 & 3 & 0 & 0 & 19 & 1,53 & 1,00 & 3,00 & 0,77 \\
\hline & Não Acreditados & 15 & 0 & 4 & 1 & 3 & 23 & 2,00 & 1,00 & 5,00 & 1,51 \\
\hline \multirow{2}{*}{$\begin{array}{l}\text { Planejamento } \\
\text { Estratégico }\end{array}$} & Acreditados & 1 & 1 & 0 & 1 & 16 & 19 & 4,58 & 5,00 & 5,00 & 1,12 \\
\hline & Não Acreditados & 2 & 0 & 9 & 5 & 7 & 23 & 3,65 & 4,00 & 5,00 & 1,19 \\
\hline \multirow{2}{*}{$\begin{array}{l}\text { Simulação de } \\
\text { Resultados }\end{array}$} & Acreditados & 4 & 1 & 0 & 2 & 12 & 19 & 3,89 & 5,00 & 5,00 & 1,70 \\
\hline & Não Acreditados & 7 & 1 & 4 & 7 & 4 & 23 & 3,00 & 3,00 & 5,00 & 1,54 \\
\hline \multirow{2}{*}{$\begin{array}{l}\text { Teoria das } \\
\text { Restrições }\end{array}$} & Acreditados & 10 & 7 & 1 & 1 & 0 & 19 & 1,63 & 1,00 & 4,00 & 0,83 \\
\hline & Não Acreditados & 15 & 1 & 4 & 3 & 0 & 23 & 1,78 & 1,00 & 4,00 & 1,17 \\
\hline
\end{tabular}

Legenda: NP e 1 = Não há planos para adoção; AD e 2 = Avaliou e descartou; PA e 3 = Em processo de avaliação; AI e 4 = Adoção inicial; AP e 5 = Adoção plena; TOT = Total; MÉD = Média; MED = Mediana; $\mathrm{DP}=$ Desvio padrão; $\mathrm{BSC}=$ Balanced Scorecard $; \mathrm{ABC}=$ Custeio Baseado em Atividades; $\mathrm{ABM}=\mathrm{Gestão}$ Baseada em Atividade; EVA = Economic Value Added $; \mathrm{VBM}=$ Gestão Baseada em Valor; JIT = Just in Time.

Fonte: Dados da Pesquisa. 
Verifica-se, por meio da média e pelo baixo desvio padrão, que a adoção plena de artefatos modernos de contabilidade gerencial, nos hospitais acreditados, tem predominância no Benchmarking $(4,53)$ e Planejamento Estratégico (4,58). Quanto à adoção plena de artefatos nos hospitais não acreditados, os resultados não revelaram predominância, apenas em adoção inicial com o Planejamento Estratégico $(3,65)$. Nesse contexto, fica evidente uma maior adoção plena de artefatos modernos pelos hospitais que são acreditados.

Os dados remetem ao entendimento de que a necessidade de constante aprimoramento gerencial para garantir a excelência organizacional em prol da segurança do paciente, requerida pela acreditação hospitalar, exige que os gestores busquem apoio informacional em artefatos de contabilidade gerencial. Ou seja, sendo a acreditação um sistema de gestão que focaliza a essência da atividade hospitalar - o paciente - para que seja operacionalizada com sucesso é necessário que toda a organização opere com eficiência e eficácia. Nessa condição, os artefatos de contabilidade gerencial passam a ser introduzidos e utilizados de forma a garantir resultados condizentes com o status de hospital acreditado.

Os resultados aqui evidenciados são similares aos achados de Cardoso e Martins (2012) e Xavier e Carmo Filho (2015), de que há diferença no uso dos artefatos de contabilidade entre as organizações hospitalares acreditadas e as não acreditadas. O presente estudo avança em relação aos estudos anteriores ao evidenciar que a predominância na adoção dos artefatos de contabilidade gerencial pelas organizações acreditadas em comparação às não acreditadas ocorreu na maioria dos artefatos, nos estudos anteriores, cuja amostra era restrita a uma única cidade. A superioridade foi em um número pequeno de artefatos e a diferença foi pouco expressiva.

A existência de relação entre a acreditação e a utilização de artefatos tradicionais e modernos nos hospitais da Região Sul do Brasil foi verificada com a Análise de Correspondências Múltiplas (ACM) e com o teste de 
Kruskal-Wallis, mas de forma preliminar foi aplicado o Alfa de Cronbach para verificar a consistência das variáveis do constructo, conforme mostra a Tabela 6.

Tabela 6 - Alfa de Cronbach do Constructo

\begin{tabular}{cc}
\hline & Caracterização do Constructo \\
Alfa de Cronbach & 0,928 \\
Número de variáveis & 22 \\
\hline
\end{tabular}

Fonte: Dados da pesquisa, Software SPSS® 22.0.

Segundo Hair Jr. et al. (2009), o teste Alfa de Cronbach é um tipo de confiabilidade que é empregado para avaliar uma escala somada em que várias afirmações são adicionadas para formar um escore total para um constructo. Hair Jr. et al. (2009, p. 100) destacam que o Alfa de Cronbach é uma "medida de confiabilidade que varia de 0 a 1 , sendo os valores de 0,60 a 0,70 considerados o limite inferior de aceitabilidade". Assim sendo, o Alfa de Cronbach de 0,928 observado revela uma excelente confiabilidade e consistência do constructo do presente estudo.

Na sequência foi realizada a Análise de Correspondências Múltiplas sobre as variáveis categóricas, das questões em conjunto de acreditação e utilização dos artefatos, para realização de correlação, conforme mapa perceptual apresentado na Figura 1, após a identificação dos fatores para análise. 
Figura 1 - Mapa perceptual da associação entre acreditação e adoção de artefatos de contabilidade

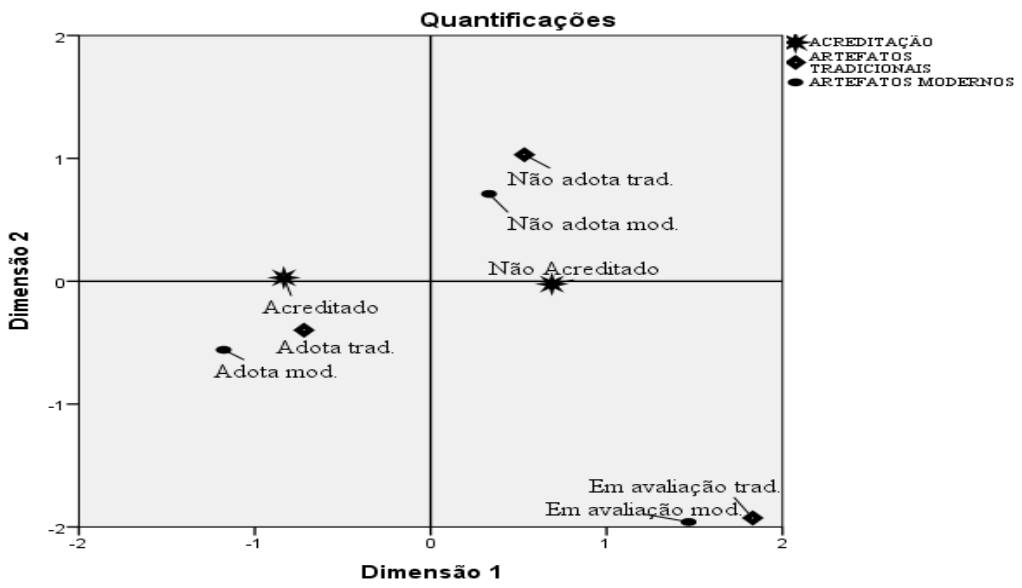

Legenda: Acreditado=Hospital possui acreditação; Não Acreditado=Hospital não possui acreditação; Não adota trad.=Não adota artefatos tradicionais; Em avaliação trad.=Artefatos tradicionais em avaliação; Adota trad.=Adota artefatos tradicionais; Não adota mod.=Não adota artefatos modernos; Em avaliação mod.=Artefatos modernos em avaliação; Adota mod.=Adota artefatos modernos.

Fonte: Dados da Pesquisa, Software SPSS® 22.0.

O mapa perceptual da Figura 1 está subdividido em quatro quadrantes, destacando-se que a distribuição dos pontos possibilita a análise graficamente da associação entre a certificação de acreditação dos hospitais brasileiros da Região Sul com a utilização de artefatos de contabilidade gerencial. Os 42 hospitais estão representados no mapa perceptual por meio das variáveis. Quanto mais afastados do centroide e mais próximos estiverem das variáveis, maior é o poder associativo.

De acordo com a Figura 1, constata-se a formação de dois grupos, no quadrante à esquerda, parte inferior, os achados revelam que há uma associação dos hospitais que possuem acreditação com uma maior adoção de artefatos tradicionais e modernos de contabilidade gerencial. Já no quadrante à direita, parte superior, como a divisão entre modernos e 
tradicionais compreende um conjunto de artefatos e há a constatação de baixa adoção de artefatos pelos hospitais não acreditados, os resultados mostram que essas organizações tendem para a não adoção dos artefatos de uma forma conjunta.

Para dar mais consistência nos resultados, nas Tabelas 7 e 8 são apresentados os resultados do teste de Kruskal-Wallis aplicado ao constructo da pesquisa.

Tabela 7 - Teste Kruskal-Wallis para a relação entre a acreditação e a utilização de artefatos da contabilidade gerencial tradicionais

\begin{tabular}{|c|c|c|c|c|c|c|}
\hline \multicolumn{2}{|c|}{$\begin{array}{l}\text { Questões/ } \\
\text { Artefatos }\end{array}$} & Q30-CP & Q31-CA & Q32-CV & $\begin{array}{c}\text { Q33- } \\
\text { DESC }\end{array}$ & $\begin{array}{l}\text { Q34- } \\
\text { MC }\end{array}$ \\
\hline \multirow{6}{*}{$\begin{array}{l}\text { Q6-Acre- } \\
\text { ditação }\end{array}$} & $\mathrm{X}^{2}$ & 8,442 & 10,809 & 2,511 & 8,980 & 12,823 \\
\hline & Sig. & 0,004 & 0,001 & 0,113 & 0,003 & 0,000 \\
\hline & & & & & & \\
\hline & & Q35-ORÇ & Q36-PT & Q37-RSI & Q38-VP & \\
\hline & $\mathrm{X}^{2}$ & 3,110 & 4,130 & 0,284 & 1,860 & \\
\hline & Sig. & 0,078 & 0,042 & 0,594 & 0,173 & \\
\hline
\end{tabular}

Legenda: Q.30-CP = Custeio Padrão; Q31-CA = Custeio por Absorção; Q32-CV = Custeio Variável; Q33-DESC = Descentralização; Q34-MC = Moeda Constante; Q35-ORÇ = Orçamento; Q36-PT = Preço de Transferência; Q37-RSI = Retorno sobre Investimento; Q38-VP $=$ Valor Presente.

Fonte: Dados da pesquisa, Software SPSS® 22.0.

Com base na Tabela 7, na análise do teste de Kruskal-Wallis, comparado na questão "acreditação" (Q6), os níveis de significâncias (p é $\leq 0,05$ ) evidenciam que a acreditação hospitalar exerce influência na utilização da maioria dos artefatos tradicionais de contabilidade gerencial, tais como: Custeio Padrão, Custeio por Absorção; Descentralização, Moeda Constante e Preço de Transferência. No estudo de Xavier e Carmo Filho (2015), apenas as variáveis Custeio Padrão e Descentralização apresentaram significância, constatando-se que nesses dois artefatos a maior adoção foi identificada nas organizações não acreditadas. 
Tabela 8 - Teste Kruskal-Wallis para a relação entre a acreditação e a utilização de artefatos da contabilidade gerencial modernos

\begin{tabular}{|c|c|c|c|c|c|c|c|}
\hline \multicolumn{2}{|c|}{$\begin{array}{l}\text { Questões/ } \\
\text { Artefatos }\end{array}$} & Q39-BSC & Q40-BEN & Q41-ABC & Q42-CM & \multirow{2}{*}{$\begin{array}{c}\text { Q43-ABM } \\
0,905\end{array}$} & \multirow{2}{*}{$\begin{array}{c}\text { Q44-EVA } \\
3,996 \\
\end{array}$} \\
\hline \multirow{6}{*}{$\begin{array}{l}\text { Q6-Acre- } \\
\text { ditação }\end{array}$} & $\mathrm{X}^{2}$ & 10,443 & 13,056 & 10,396 & 6,594 & & \\
\hline & Sig. & 0,001 & 0,000 & 0,001 & 0,010 & 0,341 & 0,046 \\
\hline & & & & & & & \\
\hline & & Q45-VBM & Q46-JIT & Q47-Kaizen & Q48-PE & Q49-SIM & Q50-TR \\
\hline & $\mathrm{X}^{2}$ & 1,717 & 0,944 & 0,268 & 9,388 & 5,154 & 0,017 \\
\hline & Sig. & 0,190 & 0,331 & 0,604 & 0,002 & 0,023 & 0,898 \\
\hline
\end{tabular}

Legenda: Q.39-BSC = Balanced Scorecard; Q40-BEN =Benchmarking; Q41-ABC = Custeio Baseado em Atividades; Q42-CM = Custeio Meta; Q43-ABM = Gestão Baseada em Atividade; Q44-EVA = Economic Value Added; Q45-VBM = Gestão Baseada em Valor; Q46-JIT = Just in Time; Q47-Kaisen = Kaisen; Q48-PE = Planejamento Estratégico; Q49-SIM = Simulação; Q50.TR = Teorias das Restrições.

Fonte: Dados da pesquisa, Software SPSS® 22.0.

Conforme a Tabela 8, na comparação da questão "acreditação" ( $Q$ 6) com as questões que contemplam a utilização dos artefatos de contabilidade gerencial modernos, os achados indicam que a acreditação hospitalar exerce influência na utilização da maioria dos artefatos de contabilidade gerencial modernos, como o: BSC, Benchmarking; ABC; Custeio Meta; EVA; Planejamento Estratégico e Simulação de Resultados. No achado de Xavier e Carmo Filho (2015), apenas as variáveis BSC, ABC e JIT apresentaram significância, destacando-se que nos dois últimos artefatos predominou a adoção pelas organizações não acreditadas.

Assim sendo, com base no exposto, os resultados sugerem que existe uma relação significativa entre a acreditação dos hospitais da Região Sul do Brasil com a utilização de artefatos tradicionais e modernos de contabilidade gerencial. Dessa forma, não é possível rejeitar as hipóteses $H_{2 a}$, de que existe relação entre a certificação de acreditação dos hospitais da Região Sul do Brasil e a utilização de artefatos tradicionais de contabilidade gerencial e 
$H_{2 b}$, de que existe relação entre a certificação de acreditação dos hospitais da Região Sul do Brasil e a utilização de artefatos modernos de contabilidade gerencial.

Ressalta-se que a acreditação contribui para que os hospitais aperfeiçoem e promovam a melhoria na qualidade do atendimento ao paciente, o que exige qualificação dos processos internos (XAVIER; CARMO FILHO, 2015). Esses processos estão relacionados com o processo de controle do planejamento estratégico, que é realizado por meio de artefatos de contabilidade gerencial tradicionais ou modernos, conforme a necessidade informacional (NOVAES, 2007; XAVIER; CARMO FILHO, 2015). De modo geral, as organizações hospitalares utilizam dos artefatos gerenciais para efetivar práticas de gerenciamento que contribuem para a melhoria de seus processos internos visando a alcançar a certificação por acreditação hospitalar, ou seja, a utilização de artefatos tradicionais e modernos contribui para o processo de acreditação hospitalar (ROGGENKAMP; WHITE; BAZZOLI, 2005; CARDOSO; MARTINS, 2012).

\section{Conclusões e Recomendações}

Esta pesquisa teve como objetivo verificar a relação da acreditação com o isomorfismo institucional e com os artefatos tradicionais e modernos da contabilidade gerencial em hospitais da Região Sul do Brasil.

Levando em consideração que a certificação no Brasil já existe há cerca de 16 anos, os hospitais acreditados e detentores de serviços de alta complexidades são os que possuem um maior tempo de acreditação, de 7 a 9 anos. Visto que as organizações de alta complexidade exigem mais investimento e controle dos recursos, necessitam também de mais artefatos de contabilidade para o processo de gestão, o que pode se refletir na qualidade dos serviços. 
Os resultados apontaram que o ambiente organizacional em que os hospitais estão inseridos foi considerado como sendo, predominantemente, estável e previsível, e caracterizado como normativo. Tendo em vista a revisão de literatura realizada, pressupõe-se que isso se deve ao fato de que as mudanças provocadas pelo ambiente externo influenciam no ambiente organizacional interno dos hospitais, ou seja, as mudanças ocorreram devido ao fato de a ONA decretar o estabelecimento de padrões de qualidade para que os processos sejam organizados de um determinado modo. Dessa forma, os achados sugerem que a adoção voluntária da acreditação hospitalar pelos hospitais investigados ocorre em virtude de um fator normativo externo legitimado na visão dos profissionais da área, além de estar atrelada a uma necessidade interna e estratégica.

$\mathrm{Na}$ análise descritiva dos artefatos o estudo mostrou que os hospitais que possuem acreditação já fazem uso ou estão em processo de adoção de uma quantidade maior de artefatos de contabilidade gerencial, quando comparados aos não acreditados. Para uma confirmação estatística de predominância no uso e associação, na realização da análise de correspondências múltiplas, foi constatada a existência de associação dos hospitais que possuem acreditação com uma maior adoção de artefatos tradicionais e modernos de contabilidade gerencial.

Para dar mais consistência e detalhamento nos resultados, o teste de Kruskal-Wallis revelou que a acreditação hospitalar exerce influência na utilização da maioria dos artefatos tradicionais de contabilidade gerencial, como o Custeio Padrão, Custeio por Absorção; Descentralização, Moeda Constante e Preço de Transferência. A mesma influência foi constatada na utilização dos seguintes artefatos modernos: Balanced Scorecard, Benchmarking; ABC; Custeio Meta; EVA; Planejamento Estratégico e Simulação de Resultados.

Ao considerar que os hospitais acreditados fazem um uso maior de artefatos tradicionais e modernos de contabilidade gerencial e que o ambiente organizacional em que estão inseridos foi considerado estável e previsível, os resultados do estudo confirmam a existência de uma relação 
significativa entre a acreditação dos hospitais brasileiros da Região Sul e as pressões isomórficas, em especial as pressões normativas, bem como entre a acreditação e o uso de artefatos tradicionais e modernos de contabilidade gerencial. Esses achados corroboram com os de Garrido, Tacchini e Saltorato (2014), de que as pressões sobre as organizações hospitalares em favor do aprimoramento de suas práticas deixam de advir apenas das exigências legais e governamentais, e com os de Xavier e Carmo Filho (2015), de que há diferença no uso dos artefatos de contabilidade entre as organizações hospitalares acreditadas e as não acreditadas.

Esta pesquisa contribui para a literatura da área, tendo em vista que indicou alguns dos agentes e possíveis motivos (fatores) que levam as empresas a legitimar seus procedimentos e atividades por meio do processo de certificação por acreditação. Contribui também para mostrar que as organizações hospitalares acreditadas, diante de um uso mais intensivo de artefatos tradicionais e modernos de contabilidade gerencial, possuem maior tendência para melhorias de seus processos internos, resultados e melhor gestão dos recursos disponíveis, e ainda, têm mais opções para selecionar artefatos específicos para determinadas decisões.

Cabe destacar como limitações desta pesquisa a escolha da amostra formada por hospitais da Região Sul do Brasil, pois poderiam ser analisados hospitais localizados em outros Estados brasileiros, ou mesmo analisar hospitais localizados em outros países, pois pode haver diferenças em termos de utilização dos artefatos da contabilidade gerencial, o tipo de isomorfismo, como também quanto à relação entre ambos.

Para a realização de futuras pesquisas sugere-se a inclusão de outras variáveis caracterizadas como motivos ou fatores institucionais, ou outros fatores ambientais externos. Além disso, propõe-se que sejam investigados motivos que expliquem a preferência das organizações hospitalares em adotar voluntariamente o sistema de acreditação apresentado pela ONA, em 
detrimento de outros modelos. Sugere-se também a reaplicação do estudo em datas futuras, inclusive abrangendo outras regiões, para confirmar as tendências dos achados da presente pesquisa.

\section{Referências}

ALONSO, Luiza Beth Nunes et al. Acreditação hospitalar e a gestão da qualidade dos processos assistenciais. Perspectivas em Gestão \&̊ Conhecimento, 4(2), p. 34-49, 2014. BAUM, J. A. C. Ecologia organizacional. In: CALDAS, M.; FASHIN, R.; FISHER, T. Handbook de Estudos Organizacionais. São Paulo: Atlas, 2010.

BURNS, J.; SCAPENS, R. W. Conceptualizing management accounting change: an institutional framework. Management Accounting Research, 11(1), p. 3-25, 2000.

CARDOSO, S. M.; MARTINS, V. F. Sistemas de custos estão presentes nos hospitais brasileiros que passaram pelo processo de acreditação hospitalar? Revista $\mathrm{GeTe} C$, 1(2), 2012.

CUNHA, P. R.; SANTOS, V.; BEUREN, I. M. Artigos de periódicos internacionais que relacionam teoria institucional com contabilidade gerencial. Perspectivas Contemporâneas, 10(2), p. 1-23, 2015.

DEPARTAMENTO DE INFORMÁTICA DO SUS (Datasus). Cadastro Nacional de Estabelecimentos de Saúde (CNES). (2015). Disponível em: <http://cnes2.datasus. gov.br/Mod_Ind_Unidade .asp>. Acesso em: $1^{\circ}$ nov. 2015.

DIMAGGIO, P.; POWELL, W. The ironcage revisited: institutional isomorphism and collective rationality in organizational fields. American Sociological Review, 48(2), p. 147-160, 1983.

DIMAGGIO, P. J.; POWELL, W. A gaiola de ferro revisitada: isomorfismo institucional e racionalidade coletiva nos campos organizacionais. Revista de Administração de Empresas, 45(2), p. 74-89, 2005.

DOS REIS, L. G.; REIF, E.; MARASSI, R. B. A institucionalização de práticas de contabilidade gerencial com auxílio de uma consultoria gerencial em uma rede de farmácias. Revista da Micro e Pequena Empresa, 9(3), p. 65-81, 2015.

DOS SANTOS, V.; DOROW, D. R.; BEUREN, I. M. Práticas gerenciais de micro e pequenas empresas. Revista Ambiente Contábil, 8(1), p. 153-186, 2016.

EMIDIO, L. et al. Acreditação hospitalar: estudo de casos no Brasil. Perspectivas em Gestão ङ̈ Conhecimento, v. 3, n. 1, p. 98-113, 2013.

ESPEJO, M. M. S. B. Perfil dos atributos do sistema orçamentário sob a perspectiva contingencial: uma abordagem multivariada. 216f. Tese de Doutorado. Tese (Doutorado em Ciências Contábeis) - Programa de Pós-Graduação em Ciências Contábeis, Faculdade de Economia, Administração e Contabilidade da Universidade de São Paulo, São Paulo, 2008. 
ESPEJO, M. M. S. B. et al. Uma análise crítico-reflexiva da compreensão da adoção dos artefatos de contabilidade gerencial sob uma lente alternativa: a contribuição de abordagens organizacionais. Revista de Contabilidade e Organizações (RCO), 3(5), p. 25-43, 2009.

FÁVERO, L. P. et al. Análise de dados: modelagem multivariada para tomada de decisões. Rio de Janeiro: Elsevier, 2009.

FELDMAN, L. B.; GATTO, M. A. F.; CUNHA, I. C. K. O. História da evolução da qualidade hospitalar: dos padrões a acreditação. Acta Paulista de Enfermagem, 18(2), p. 213-219, 2005.

FREZATTI, F. Management accounting profile of firms located in Brazil: a field study. Brazilian Administration Review, 2(1), p. 73-87, 2005.

GARRIDO, G.; TACCHINI, G. A. V.; SALTORATO, P. Acreditação hospitalar: uma análise institucional da postura assumida pelas instituições de saúde. In: SIMPÓSIO DE ADMINISTRAÇÃ̃O DA PRODUÇÃO, LOGÍSTICA E OPERAÇÕES INTERNACIONAIS. 2014, São Paulo. Anais... São Paulo: Simpoi, 2014.

GRANLUND, M.; LUKKA, K. It's a small world of management accounting practices. Journal of Management Accounting Research, 10(1), p. 153-179, 1998.

GRYNA, F. M.; CHUA, R. C. H.; DEFEO, J. A. Juran's quality planning and analysis. 5. ed. Nova York: McGraw-Hill, 2007.

GUERREIRO, R.; FREZATTI, F.; CASADO, T. Em busca de um melhor entendimento da contabilidade gerencial através da integração de conceitos da psicologia, cultura organizacional e teoria institucional. Revista de Contabilidade \& Finanças, Edição Comemorativa, p. 7-21, 2006.

GUERREIRO, R.; CORNACHIONE JR., E.; SOUTES, D. O. Empresas que se destacam pela qualidade das informações a seus usuários externos também se destacam pela utilização de artefatos modernos de contabilidade gerencial. Revista de Contabilidade छ̈ Finanças, 22(55), p. 88-113, 2011.

HAIR JR, J. F. et al. Análise multivariada de dados. 6. ed. Porto Alegre: Bookman, 2009. HARRIS, J. E. The internal organization of hospitals: some economic implications. The Bell Journal of Economics, 8(2), 467-482, 1977.

HEUVEL, J. V. D.; NIEMEIJER, G. C.; DOES, R. J. M. M. Measuring healthcare quality: the challenges. International journal of health care quality assurance, 26(3), p. 269-278, 2013.

HEALTH SERVICES ACCREDITATION (IQG). Instituições acreditadas. Disponível em: <http://www2.iqg.com.br/site/principal>. Acesso em: 18 jan. 2016.

HORNGREN, C. T.; SUNDEM, G. L.; STRATTON, W. O. Introduction to Management Accounting. 10. ed. Prentice Hall: Upper Saddle River, 2004.

KAPLAN, R. S. Measuring manufacturing performance: a new challenge for managerial accounting research. The Accounting Review, 58(4), p. 686-705, 1983. 
LOUDERBACK, J. G.; HOLMEN, J.; DOMINIAK, G. Managerial accounting. 9. ed. Cincinnati: South-Western College Publisher, 2000.

LUCAS, M. Standard costingand its role in today's manufacturing genvironment. Management Accounting, 75(4), p. 32-37, 1997.

MAMEDIO, D. F. Isomorfismo institucional em organizações de saúde: a gestão do processo de acreditação hospitalar. In: ENEGEP - Encontro Nacional de Engenharia de Produção, Infraestrutura e Desenvolvimento Sustentável 34., 2014. Curitiba. Anais... Curitiba: Enepeg, 2014.

MAROCO, J. Análise estatística com utiliæação do SPSS. 3. ed. Lisboa: Sílabo, 2007.

MCKINLEY, W.; MONE, M. Organization theory. Oxford: Oxford University Press, 2003.

MEYER, J.; ROWAN, B. Institutionalized organizations: formal structure as myth and ceremony. American Journal of Sociology, 83(2), p. 340-363, 1977.

MEZOMO, J. C. Qualidade hospitalar: reinventando a administração do hospital. São Paulo: Cedas, 1992.

MORAIS, C. G. X. et al. Registros de enfermagem em prontuário e suas implicações na qualidade assistencial segundo os padrões de acreditação hospitalar: um novo olhar da auditoria. Revista Acreditação: Acred, 5(9), p. 64-84, 2015.

NIMEIJER, G. C. Process improvement in healthcare. Holanda: Universiteit van Amsterdam, 2012.

NOVAES, H. M. O processo de acreditação dos serviços de saúde. Rev. Adm. Saúde, 9(37), p. 133-140, 2007.

O'BRIEN, N.; RENNEBOHM, H.; LOWE, C. Organizational schema for management control of quality care: a program perspective. The Canadian Journal of Program Evaluation, 2(2), p. 11-21, 1987.

ORGANIZAÇÃO NACIONAL DE ACREDITAÇÃO (ONA). Manual das organizações prestadoras de serviços de saúde. Brasília: ONA, 2010. V. 1.

. Hospitais acreditados, 2015. Disponível em: <https://www.ona.org.br/Inicial>. Acesso em: 10 out. 2015.

OTLEY, D. Management control in contemporary organizations: towards a wider framework. Management Accounting Review, 5(1), p. 289-299, 1994.

RODNISKI, C. M. et al. Uso das práticas de contabilidade gerencial em propriedades rurais: um estudo multicaso na Região Oeste Catarinense. Unoesc Ë Ciência-ACSA, 5(1), p. 113-121, 2014.

ROGGENKAMP, S. D.; WHITE, K. R.; BAZZOLI, G. J. Adoption of hospital case management: economic and institutional influences. Social Science \&્ Medicine, 60(11), p. 2.489-2.500, 2005. 
SANT'ANA, C. F.; SANTOS, C. A.; CUNHA, P. R. Relação dos fatores comportamentais nos métodos de contabilidade gerencial nos hotéis de Santa Catarina. Turismo-Visão e Ação, 19(1), p. 154-184, 2017.

SANTOS, A. R. Diagnóstico institucional dos fatores que concorrem para o isomorfismo das práticas de contabilidade gerencial utilizadas pelas organizaçôes do setor elétrico brasileiro. 2008. 246 f. Dissertação (Mestrado em Ciências Contábeis) UFPR - Universidade Federal do Paraná, Curitiba, 2008.

SOUZA, M. A.; LISBOA, L. P.; ROCHA, W. Práticas de contabilidade gerencial adotadas por subsidiárias brasileiras de empresas multinacionais. Revista Contabilidade \& Finanças, 14(32), p. 40-57, 2003.

SULAIMAN, M.; NAZLI NIK AHMAD, N.; ALWI, N. Management accounting practices in selected asian countries: A review of the literature. Managerial Auditing Journal, 19(4), p. 493-508, 2004.

VERHAGEM, J. A. Análise do impacto da implementação das normas internacionais de contabilidade no Brasil: estudo de caso em uma grande empresa. 2011. 126 f. Dissertação (Mestrado em Ciências Contábeis) - Programa de Pós-Graduação em Ciências Contábeis da Universidade Regional de Blumenau, Blumenau, 2011.

VIANA, M. F. et al. Processo de acreditação: uma análise de organizações hospitalares. Revista de Administração Hospitalar e Inovação em Saúde, 3(6), p. 35-45, 2011.

XAVIER, R. V.; CARMO FILHO, M. M. Uso dos artefatos de contabilidade gerencial: Comparativo entre os hospitais acreditados no Brasil com os não acreditados da cidade de Manaus (AM). Revista Ambiente Contábil, 7(2), p. 248-269, 2015. 